\title{
СИСТЕМА ИНВЕСТИЦИОННЫХ РЕШЕНИЙ ПО УВЕЛИЧЕНИЮ СТОИМОСТИ КОММЕРЧЕСКОГО БАНКА ПАО «СБЕРБАНК»
}

\begin{abstract}
THE SYSTEM OF INVESTMENT DECISIONS
TO INCREASE THE VALUE OF A
COMMERCIAL BANK PJSC "SBERBANK"
E. Gancheva

Summary. The article considers an investment - innovative solution to increase the market value of a commercial bank. The article also put forward a proposal to create a trading robot to increase the value of Sberbank PJSC. Based on the innovative idea proposed in the article, a trading robot for banks will be able to act as a special program that will automatically process over 50 applications per day from corporate clients. In addition, a trading robot can process applications for not only loans from corporate clients, but also applications for the stock exchange, and analyze market conditions. As a result, this investment-innovative solution will help the bank become a more financially stable organization, and at the same time increase the market value of the company. Based on the information that Sberbank PJSC carries out currency trading operations, the trading robot will be able to manage currency risk through an additional function - hedging. One of the methods of hedging currency risk is the conclusion of futures contracts and their verification of the deviation of the exchange rate on the transaction. A trading robot will be able to easily carry out such calculations when choosing a futures contract, based on conditions and prices. Thus, choosing the most effective futures contract for Sberbank, the trading robot will minimize the organization's currency risk.
\end{abstract}

Keywords: commercial bank market value, securities, investments, business valuation, futures, futures contacts, risk hedging.

\section{Введение}

B современном мире крайне важно придумывать наилучшие инвестиционные решения, способные увеличить рыночную стоимость той или иной компании. Рыночная стоимость компании может быть увеличена путем создания новых инновационных проектов, которые в дальнейшем будут способствовать процветанию фирмы и ее успешному функционированию.
Ганчева Елена Александровна

Финансовый университет при Правительстве

Российской Федерации

elenakmk1@gmail.com

Аннотация. В статье рассмотрено инвестиционное - инновационное решение по увеличению рыночной стоимости коммерческого банка. В статье также было выдвинуто предложение по созданию торгового робота для увеличения стоимости компании ПАО «Сбербанк». Исходя из инновационной идеи, предложенной в статье, торговый робот для банков сможет выступать в качестве специальной программы, которая автоматически будет обрабатывать свыше 50 заявок в день от корпоративных клиентов. Кроме того, торговый робот может обрабатывать заявки не только по кредитам корпоративных клиентов, но и заявки на фондовой бирже, анализировать рыночную конъюнктуру. Как следствие, данное инвестиционно-инновационное решение поможет банку стать более финансово устойчивой организацией, и вместе с тем повысить рыночную стоимость компании. Исходя из информации, что ПАО «Сбербанк» осуществляет валютные торговые операции, то торговый робот будет способен управлять валютным риском через дополнительную функцию - хеджирование. Одним из способов хеджирования валютного риска является заключение фьючерсных договоров и их проверка на отклонение валютного курса по совершаемой сделке. Торговый робот сможет легко проводить такие расчёты при выборе фьючерсного контракта, основываясь на условиях и ценах. Тем самым, выбирая самый эффективный для Сбербанка фьючерсный контракт, торговый робот будет минимизировать валютный риск организации.

Ключевые слова: рыночная стоимость коммерческого банка, ценные бумаги, инвестиции, оценка бизнеса, фьючерсы, фьючерсные контакты, хеджирование риска.

Актуальность темы исследования обусловливается возрастающей ролью инвестиций, как ключевого фактора, способного увеличить стоимость бизнеса компании.

Цель статьи состоит в исследовании вложений в инновационный проект, связанный с автоматизацией инвестиционных операций, который способен помочь в решении множества проблем, связанных с облегчением осуществления операций на рынке и одновременным принесением прибыли. 
Данная цель предполагает решение следующих задач:

- выделение ключевых инновационных-инвестиционных решений, влияющих на рост стоимости коммерческого банка;

- внедрение торгового робота в работу банка с функцией хеджирования рисков;

- определение эффективности плана хеджирования валютного курса.

Повышение активности коммерческих банков на инвестиционном рынке обуславливает формирование системы инновационных процессов. Эффективное освоение инноваций происходит именно на инвестиционном и фондовом рынках, поскольку новые направления деятельности кредитных организаций предполагают распространение новых технологий, одной из которых выступает Интернет-торговля. Благодаря так называемому Интернет-трейдингу существует возможность применения новых информационных решений в бизнесе, связанном с инвестиционной деятельностью. Потенциальному инвестору в рамках Интернет-трейдинга предоставляется следующий набор услуг:

1. Торговые операции с финансовыми инструментами, которые подразумевают покупку или продажу ценных бумаг, иностранных валют;

2. Неторговые операции, которые подразумевают выдачу кредита, перевод ценных бумаг на любой счёт, реализацию безналичного платежа в какую-либо организацию;

3. Отчётность по счёту, что включает в себя получение выписок по брокерским, депозитарным, расчётно-кассовым счетам, которые содержат подробную информацию по каждой операции, максимально быстрое их отражение после осуществления и инициирования;

4. Аналитическая поддержка, которая связана с предоставлением доступа к информации, связанной с реализацией инвестиционных операций: технический анализ акций в процессе торгов, комментарии новостей и событий о деятельности компаний-эмитентов, фундаментальный анализ и оценка перспектив интересующей отрасли;

5. Консультации, представляющие собой оперативное разъяснение исполнителей по разным аспектам взаимодействия с организацией [1].

На российском фондовом рынке существуют следующие виды Интернет-трейдинговых систем:

1. Удалённые интернет-терминалы ММВБ. Особенностью данного вида является то, что они имеют спекулятивную стратегию в функционировании. В России системы Интернет-торговли предоставляли клиентам такие же возможности, как и у трейдера, который работает на биржевом терминале;
2. Системы, поддерживающие алгоритмы маржинального кредитования, которые возникли в связи с тем, что финансовые инструменты брокера учитываются на едином сводном счёте в ММВБ. Поэтому существует потребность в формировании дополнительных функциональных возможностей системы, которые состоят в расчёте достаточности собственных активов потребителя с целью обеспечения собственных обязательств, контроле за сложной системой лимитов, которая позволяет ограничить риски брокера;

3. Системы, которые воплощают концепцию единого брокерского счёта. Возникла новая конструкция брокерских систем, предоставивших возможность клиентам работать на нескольких торговых площадках, что потребовало новой технической организации;

4. Системы, предоставляющие возможность субброкерства. Существование данных систем способствовало получению региональными организациями быстрого доступа к биржам Москвы.

Национальный рынок ценных бумаг функционирует в соответствии с двумя сложившимися разновидностями Интернет-торговли:

1. Доступ к фондовому рынку для электронной торговли ценными бумагами реализуется через посредника;

2. Торговля инвестором ценными бумагами на бирже в реальный момент времени посредством специального программного обеспечения без посредника [2].

С момента внедрения новых информационно-коммуникационных технологий на биржевом рынке ценных бумаг произошли качественные изменения за счёт создания высокочастотной торговли ценными бумагами.

В подобной ситуации происходит автоматизация в процессе принятия инвестиционных решений, поскольку с помощью торгового робота анализируется рыночная информация и генерируются заявки на покупку или продажу ценных бумаг.

В современных условиях большинство кредитных организаций, имеющих лицензию на осуществление брокерской деятельности, предоставляет DMA-доступ, активно используемый трейдерами при высокочастотной торговле ценными бумагами.

Самым эффективным методом высокочастотной торговли считается именно услуга DMA, при которой можно исключить временные издержки на обработку заявки системой кредитной организации [3]. 
Таблица 1. Стратегии управления валютным риском

\begin{tabular}{|l|l|}
\hline Стратегия & Методы \\
\hline Уклонение от риска & Отказ от проведения операций в иностранной валюте \\
\hline Принятие риска & Создание резервов для погашения убытков (самофинансирование) \\
\hline Приобретение дополнительной информации & Прогнозирование валютных курсов \\
\hline Ограничение риска & Лимитирование, диверсификация \\
\hline Передача риска & Перенос риска, страхование, хеджирование \\
\hline
\end{tabular}

Источник: составлено автором

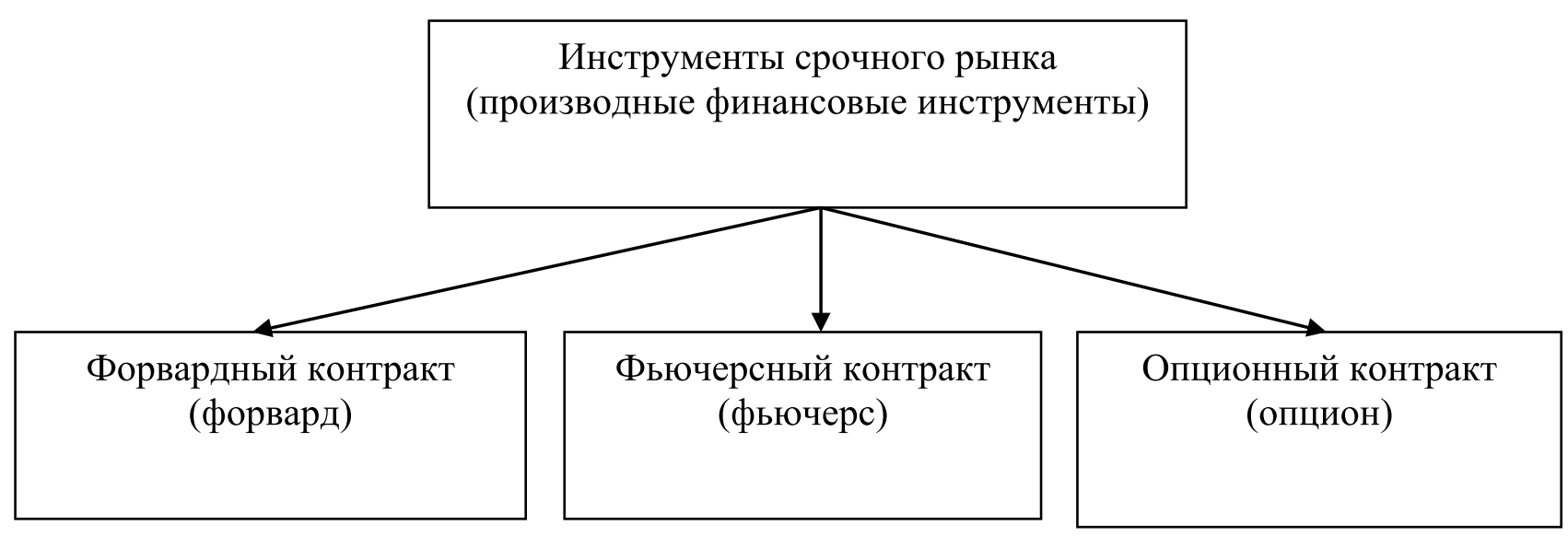

Рис. 1. Основные инструменты хеджирования валютного риска в ПАО «Сбербанк» Источник: составлено автором

Автоматизация инвестиционных операций может помочь в решении множества проблем, связанных с облегчением осуществления операций на рынке и одновременным принесением прибыли. Торговые роботы обладают следующими преимуществами:

1. Обрабатывают огромные объёмы данных, управление которыми не подвластно отдельному человеку либо группе людей;

2. Имеют высокое быстродействие, поскольку обрабатывают информационный поток механически;

3. Непрерывно работают, так как не подвержены психологическому состоянию;

Поэтому для развития операций в других банках и кредитного портфеля для увеличения рыночной стоимости ПАО «Сбербанк» необходимо внедрить торгового робота, обладающего технологией DMA. Но здесь нужно учитывать тот факт, что механическая обработка огромного информационного потока приводит к разбалансированию системы «доходность - риск». Торговый робот не может воспринимать такой подход, существующий в теории и активно применяемый на практике отделами риск-менеджмента в ПАО «Сбербанк».

Тогда следует дополнить внедрение торгового робота в работу ПАО «Сбербанк» с функцией хеджирования рисков. Рассмотрим данную опцию на примере хеджирования валютного риска, поскольку этот аспект для ПАО «Сбербанк» остаётся актуальным при ведении инвестиционных операций.

Хеджирование валютных рисков - это действия, направленные на уменьшение опасности, связанной с изменчивостью валютных курсов. Когда человек решает провести хеджирование, он, по сути, страхует себя от возможных потерь [4].

Валютный риск представляет собой вероятность наступления потерь в связи с изменением валютных курсов. 
Таблица 2. Сведения фьючерсного контракта для ПАО «Сбербанк»

\begin{tabular}{|l|l|}
\hline Параметр инструмента & Характеристика \\
\hline Краткое наименование контракта & Si-12.17 \\
\hline Краткий код & Siz7 \\
\hline Наименование контракта & Фьючерс на курс долл. США — российский рубль \\
\hline Вид контракта & Фьючерс \\
\hline Тип контракта & Расчётный \\
\hline Лот & 1000 \\
\hline Котировка & В рублях за лот \\
\hline Начало обращения & 17.03 .2016 \\
\hline Последний день обращения & 21.12 .2017 \\
\hline Дата исполнения & 21.12 .2017 \\
\hline
\end{tabular}

Источник: ФОРТC Si-12.17. URL: https://www.finam.ru/profile/mosbirzha-fyuchersy/si-12-17-siz7/.

Таблица 3. Исходные данные для хеджирования валютного курса ПАО «Сбербанк»

\begin{tabular}{|l|l|}
\hline Параметр & Характеристика \\
\hline Дата & 24.11 .2017 \\
\hline Текущий курс долл. США к рублю, установленный ЦБ РФ & 58,53 руб./долл. США \\
\hline Цель & $\begin{array}{l}\text { ПАО «Сбербанк» планирует 18.12.2017 купить } 200000 \text { долл. США } \\
\text { по курсу, который бы не сильно отличался от текущего курса }\end{array}$ \\
\hline
\end{tabular}

Источник: составлено автором

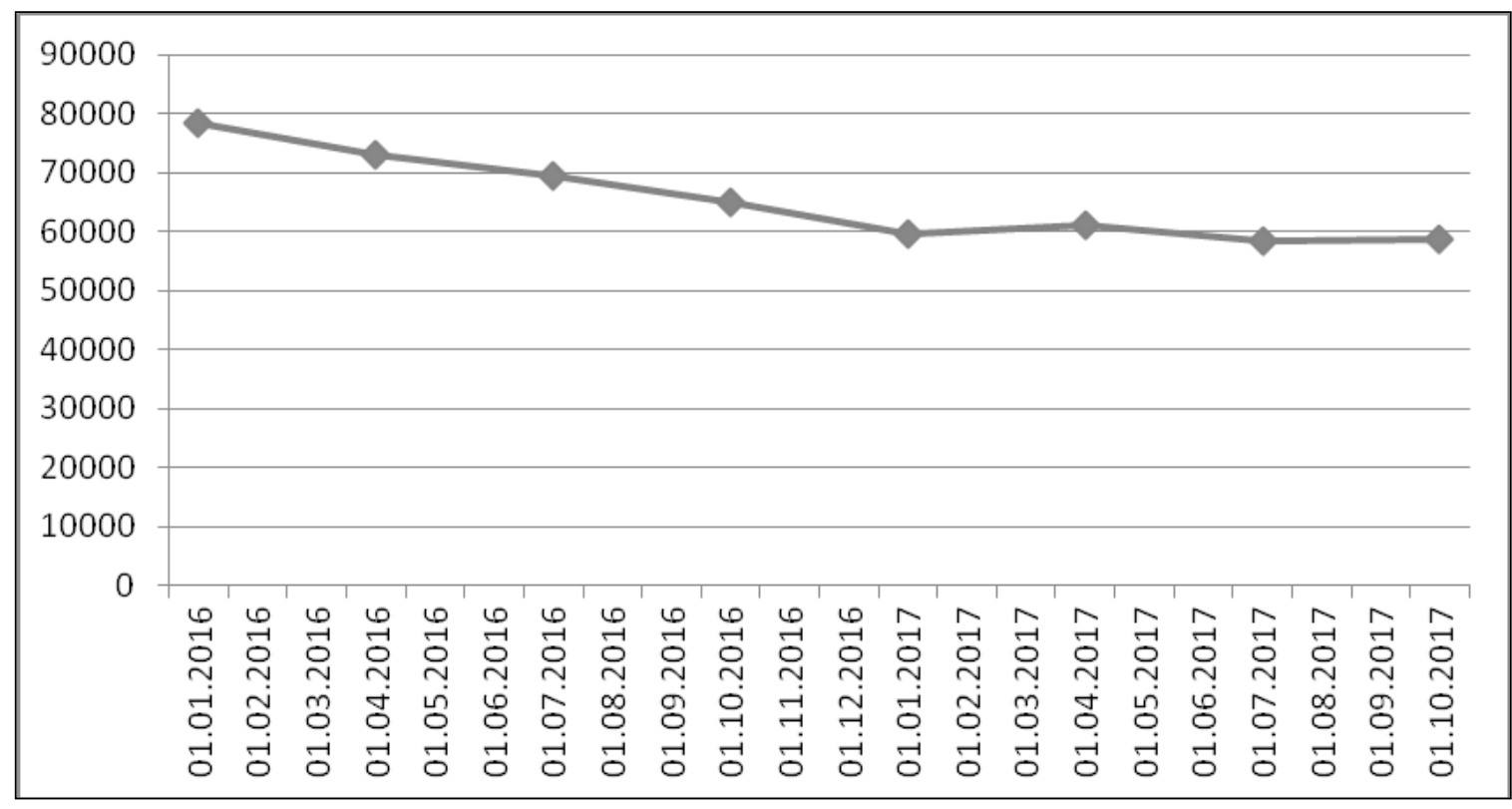

Рис. 2. Цена закрытия фьючерсного контракта ПАО «Сбербанк», руб.

Источник: ФОРТС Si-12.17. URL: https://www.finam.ru/profile/mosbirzha-fyuchersy/si-12-17-siz7/.

Управление валютным риском включает в себя несколько этапов:

1. Идентификация, обнаружение валютного риска;

2. Оценка возможных последствий, которым способствует валютный риск;
3. Выбор и количественное обоснование стратегии управления валютным риском;

4. Осуществление стратегии управления риском (табл. 1);

5. Мониторинг результатов. 
Одним из методов управления валютным риском является хеджирование - нейтрализация неблагоприятных изменений цены базового актива, которым выступает рубль [5].

Хеджирование валютного риска даст возможность ПАО «Сбербанк»:

- Избежать финансовых потерь при неблагоприятном изменении валютного курса в дальнейшем;

- Упростить процесс планирования основных финансовых показателей хозяйственной деятельности за счёт возможности фиксации будущего значения валютного курса.

На рисунке 1 представлены основные инструменты хеджирования валютного риска в ПАО «Сбербанк».

Хеджирование валютного риска будет производиться при помощи фьючерсного контракта срочного рынка.

В табл. 2 представлены сведения фьючерсного контракта для ПАО «Сбербанк».

Для хеджирования валютного курса понадобятся исходные данные, представленные в табл. 3.

Для хеджирования валютного риска в ПАО «Сбербанк» необходимо выбрать ближайший фьючерсный контракт. Для исходных данных подходит фьючерсный контракт Si-12.17, срок обращения которого заканчивается 21.12.2017 года. Его стоимость по состоянию на 24.11.2017 года составляет 58520 рублей.

На рис. 2 представлена динамика цены закрытия фьючерсного контракта ПАО «Сбербанк».

После принятия решения о выборе фьючерса необходимо определить коэффициент хеджирования, который рассчитывается по формуле (1):

$$
h=\frac{1}{1+r_{\phi} \frac{t}{B}}
$$

где $r_{\phi}$ - внутренняя доходность фьючерсного контракта (рассчитывается по формуле (2));

$t$ - время, которое остаётся до истечения контракта после завершения хеджирования;

$B-$ количество дней в году.

$r_{\phi}=\left(\frac{F}{S}-1\right) * \frac{B}{T}$

где $T$ - срок хеджирования.
В соответствии с формулой (3), получаем, что коэффициент хеджирования равен 0,9985:

$$
h=\frac{1}{1+0,1825 * \frac{3}{365}}=0,9985
$$

Следующим этапом хеджирования является определение количества контрактов, вычисляемое в соответствии с формулой (4):

$$
\text { Количество контрактов }=\frac{H S}{1000} * h
$$

где HS — хеджируемая сумма в долларах США.

На основании формул получаем, что количество контрактов составляет 200 единиц.

Оценить эффективность хеджирования валютного курса при помощи фьючерсных контрактов ПАО «Сбербанк» можно на основании формулы (5):

$$
\begin{aligned}
& R=\left(S_{t 1}-S_{t 2}\right) * H S+\left(F_{t 2}-F_{t 1}\right) * \text { Кол.контр. }= \\
& =R_{s}+R_{f}
\end{aligned}
$$

где $R_{s}$ - результат хеджирования на рынке спот;

$R_{f}$ - результат хеджирования на срочном рынке.

Результаты хеджирования представлены следующим образом:

$$
\begin{aligned}
& R_{s}=(58,53-65,72)^{*} 200000=-1438000 \text { рублей } \\
& R_{f}=(65630-58520)^{*} 200=1422000 \text { рублей } \\
& R=1422000-1438000=-16000 \text { рублей }
\end{aligned}
$$

Определим курс, по которому фактически будут куплены доллары США 18.12.2017 года:

$$
\mathrm{S}_{\text {факт }}=65,72+(58,52-65,63)^{*} 0,9985=58,61 \text { руб./долл. }
$$
США

Таким образом, планируемый план хеджирования валютного курса эффективен, поскольку цель, которая была поставлена при хеджировании, выполнена.

Таким образом, трейдеры формируют и используют торговых роботов, которые действуют по определённым алгоритмам [6]. Они способны совершать огромное количество инвестиционных сделок за краткосрочный временной период. Прибыльность каждой успешно совершенной сделки мала, однако данный аспект можно компенсировать объёмом проведённых операций. К тому же высокочастотная торговля характеризуется количеством холостых заявок, которые отправляются на биржевую площадку. Её появление обусловлено высоким уровнем автоматизации торговли и постоянным 
развитием информационного обеспечения [7]. Для расширения инвестиционных операций ПАО «Сбербанк» в кредитном портфеле и ценных бумагах необходимо внедрить торгового робота, который механически будет обрабатывать свыше 50 заявок ежедневно, однако в современных условиях торговый робот должен обладать опцией хеджирования риска, поскольку механическая обработка огромного информационного потока приводит к разбалансированию системы «доходность риск».

\section{Зак^ючение}

В современных условиях функционирования экономики инвестиции играют огромную роль в увеличении стоимости компаний. В особенности это связано с тем, что компании, заинтересованные в привлечении инвестора, стремятся продемонстрировать имеющийся потенциал создания стоимости, для обеспечения требуемой инвестором доходности [8]. Для компании, привлечение новых инвестиций позволяет внедрять новые технологии, реализовывать новые проекты, в результате чего рыночная стоимость компании увеличивается. Проведенное в работе исследование показало, что в реальности инвестиции в новые проекты, как правило, увеличит стоимость компании и она становится более дорогой на рынке.

Было разработано и выдвинуто предложение по созданию торгового робота для увеличения стоимости компании ПАО «Сбербанк». Торговый робот обладает рядом преимуществ и ранее никогда не использовался аппаратом банка. В итоге, данное инвестиционно-инновационное решение поможет ПАО «Сбербанку» стать более финансово устойчивой банковской организацией, и вместе с тем повысить рыночную стоимость компании.

\section{ЛИТЕРАТУРА}

1. Андреева Л. Е. Инновации на рынке ценных бумаг [Электронный ресурс] / Л. Е. Андреева, И. Ю. Гришин.—Режим доступа: http://www.invur.ru/index.php ?page=inconf\&cat=inconf1\&scat=fin-mech\&doc=1 (дата обращения: 19.02.2020).

2. Вуколова Е. Г. Интернет-трейдинг на российском рынке ценных бумаг / Е. Г. Вуколова, Е. И. Даньшина // Электронный научно-методический журнал Омского ГАУ. - 2016. — № 4 (7).- - С. 1-5.

3. Самохина Е. Г. Высокочастотная торговля как инновационная технология биржевой торговли на рынке ценных бумаг [Электронный ресурс] // VIP Studio. Серия: Экономика и Право.— 2016.— № 12.—Режим доступа: http://www.vipstd.ru/index.php (Дата обращения: 19.02.2019).

4. Хеджирование валютных рисков — это защита бизнеса от неблагоприятного изменения курса валют. [Электронный ресурс] — Режим доступа: https:// financc.ru/foreks/hedzhirovanie-valyutnyih-riskov-eto.html (дата обращения 21.02.2020

5. Балдина К.В.; Макриденко Е. Л., Швайка 0. И. Управление инвестициями: учебник для бакалавров.—М.: Дашков и К, 2016. — 675 с.

6. Безпалова В.В., С. А. Лочана Реструктуризация системы управления предприятия: учеб. пособие для студ. вузов, обуч. по напр. «Экономика».—- М.: Кноpyc, 2015.- 333 c.

7. Бланк И. А. Основы инвестиционного менеджмента.-М.: Омега-Л, 2013.- 265 с.

8. Виленский П.Л., Лившиц В. Н., Смоляк С. А. Оценка эффективности инвестиционных проектов: учебник для вузов. М.: Дело, 2012. - 538 с. 